\title{
Does GMVP Strategy Reduce Risk? A Global Asset Approach
}

Arben Zibri, University of New York, Tirana, Albania Agim Kukeli, Black Hills State University, USA

\begin{abstract}
This paper studies the out of sample risk reduction of global minimum variance portfolio. The analysis are drown from the discussions of Jagannathan and Ma (2003) regarding the risk reduction in US stock portfolios using portfolio constraints. We estimate the covariance matrix using the sample covariance matrix approach and derive optimal minimum variance portfolios considering upper/lower bounds and no restrictions. Results are shown under different revision frequency and transaction costs assumed. The data used are monthly indices of stocks, bonds, gold oil and spreads from 1996 until 2013. Unconstrained GMVPs result in the lowest out of sample variance, while unconstrained GMVPs of global bond portfolios performs the best in terms of risk reduction. Diversification through global asset classes result in a better strategy than international stock diversification regarding risk, as suggested by the literature.
\end{abstract}

Keywords: Portfolio Optimization; Minimum Variance; Risk Reduction; Global Assets

\section{INTRODUCTION}

nspired by the results reported by Nielsen and Aylusubramanian (2008) and Poullaouec (2008), this
research is focused on the Global Minimum Variance Portfolio (GMVP) performance of global assets.

As analytically described by Chan et al. (1999), predicting variance covariance matrix estimation from history is not necessarily inaccurate. Based on the authors, the out of sample Sharpe Ratios among different minimum variance models vary from 0.64 to 0.69 .

One of the main debates in portfolio optimization, however, is whether allowing security weights to take negative values or not. Green and Hollifield (1992) argue that extreme short or long positions, due to the dominance of the single factor in the covariance structure of returns, is unlikely to be due to sampling error. Extreme short positions, however, due to market regulations and other factors, are not always feasible solutions. Clarke et al (2011), present an analytical solution for optimal portfolio weights when short selling is not allowed. They show empirically that the portion of GMVP risk attributed to the single factor (market) model varies from $80 \%-90 \%$. This result suggests that there may be imposed some structure to the covariance matrix, which would reduce the number of parameters to be estimated.

Ledoit and Wolf $(2003,2004)$ addressed this issue by developing a shrinkage estimator model for the variance-covariance matrix, which is a weighted average of the sample covariance matrix (S) and the covariance matrix estimated using a single factor model or constant correlation model (F). They justify the approach by considering the singularity characteristic of the sample covariance matrix ${ }^{1}$ and the maximum likelihood estimators

${ }^{1}$ If the number of assets $(\mathrm{N})$ is greater than the number of observations $(\mathrm{T})$, the sample covariance matrix is singular, although the true covariance matrix may not be 
poor performance in small samples. The model, according to the authors, reduces the out of sample variance. Moreover, Ledoit and Wolf (2014) propose a nonlinear shrinkage estimator of the covariance matrix that decreases the out of sample risk as compared with other estimators suggested previously in the literature, especially the linear shrinkage one.

Jagannnathan and Ma (2003) present in their paper a different approach in estimating GMVP weights. They argue that, in case portfolio weights have no negative (maximum) constraint, such constraints have a shrinkage like effect of reducing (increasing) the covariance of constrained assets with other assets. Behr et al. (2008) argue that imposing the maximum weight constraint reduces the out of sample standard deviation of GMVP. Moreover, Behr et al. (2013) propose a set of upper and lower weight constraints that minimize MSE of the empirical variancecovariance matrix. Such constraints reduce the variance of short sale restricted and factor model minimum variance portfolios. DeMiguel et al. (2009a), prove that the model proposed by Jagannathan and Ma (2003) for estimating GMVPs performs better than other thirteen models, including shrinkage estimators, in terms of Sharpe Ratios. Bodnar et al (2014) derive a shrinkage estimator for GMVP weights that requires weak asset return distribution assumption, such as the existence of the first moments, and no imposed market structure. The estimator, according to the authors, dominates traditional ones in terms of risk reduction and performance as measured by Sharpe Ratio.

All papers on GMVP performance so far, however, have not tested risk reduction in a global scale, including many asset categories in the portfolio optimization exercise.

Following the work of Jagannathan and Ma (2003) and Behr et al. (2008), and considering the conclusions from Bodnar and Okhrin (2013), who say that GMVP investment is justified statistically for a wide range of risk aversion levels, we believe that this research is the first attempt of deriving GMVPs from a portfolio of global assets, including bonds, stocks, energy (oil) and precious metals (gold). Global assets are represented by regional indices, with the main assumption the world of investment opportunities is divided in four parts, US, Europe, Asia Pacific and Developing Nations. Minimum Variance portfolios are estimated using Markowitz (1952) sample covariance matrix of monthly indices return. The unconstrained, short-sale constrained, and upper bound constrained GMVPs are derived for the global asset portfolio, global bond portfolio and global equity portfolio, as per the methodology of Jagannathan and Ma (2003).

The risk reduction of unconstrained, short-sale constrained, and upper bound constrained minimum variance portfolios is compared between GMVPs and with the value weighted benchmark and equally weighted benchmark of global and distinct asset classes.

Results are presented for one year and three year revision frequency for three global portfolios, estimated using monthly returns. Transaction costs are included in the model, applying the methodology suggested by DeMiguel et al. (2009a).

The main results of this research are:

1. Unconstrained GMVPs achieve the highest ex-post risk reduction. This is valid for global assets, global bond, and global stock minimum variance portfolios independently from the rebalancing frequency.

2. Unconstrained GMVPs of global bond perform the best in terms of lower risk. Moreover, global asset GMVPs perform better than global stock GMVPs in terms of risk reduction independently from the assumed restrictions, transaction costs or revision frequency.

3. Global Minimum Variance Portfolios deliver lower out of sample standard deviation of returns than value weighted and equally weighted benchmarks of global assets, global bonds, and global stocks. This result is valid for all restrictions, transaction cost and revision frequencies assumed

This paper is organized as follows: next section introduces the research methodology of portfolio portfolio optimization. Section 3 there presents the data and a brief description of their statistical characteristics. Section four 
analyzes the empirical findings of the minimum variance portfolio of global assets, global equity and global bonds. Conclusions and recommendations are summarized in section five.

\section{RESEARCH METHODOLOGY}

The methodology of this paper follows closely the one used from Behr et al. (2008). This section is divided in two parts.

First it is described the variance-covariance matrix estimation approach and optimization. Then, it is briefly explained the inclusion of transaction costs.

\subsection{Portfolio Optimization}

Frequently mentioned in the finance literature, the estimation error of the variance covariance-matrix of returns is much less significant in optimization than expected return. The problem, however, still exists, and, as the work of Chan et al. (1999) points out, there is no simple answer for the model to be used in forecasting the variance covariance matrix of returns.

There are three widely used models for dealing with estimation error of the covariance matrix of returns: the factor models, shrinkage estimators and portfolio weight constrains.

In line with Jagannathan and Ma (2003), Chan et al. (1999) and DeMiguel et al. (2009a), this paper iuses the sample variance-covariance matrix estimation technique. Another reason for using such a technique is that it is very ad hoc to develop a shrinkage estimator or factor model on a global assets level and for each asset class globally. The establishment of risk factors to include in shrinkage estimators or factor models for forecasting the variance-covariance matrix of returns in this context is hard and much an empirical exercise rather than fundamental conclusion.

This work employs the minimum variance portfolio as per Markowitz (1952) portfolio selection framework. The variance-covariance matrix estimation period is a tradeoff between statistical confidence and possibility of inclusion of irrelevant data. In accordance with Chan et al. (1999) and Jagannathan et al. (2003) the estimation window is 60 months for GMVPs constructed by monthly returns. Optimization is performed on a rolling sample basis with one year and three year revision frequency.

The traditional estimator for the sample covariance matrix $\mathrm{S}$ is given by the formula:

$S=\frac{1}{T-1} \sum_{t=1}^{T}(R t-\bar{R})(R t-\bar{R})$

where $\mathrm{T}$ is the sample size, $R t$ is the $\mathrm{N} * 1$ vector of stock return at time $\mathrm{t}$, and $\bar{R}$ represents the sample mean of these returns. Given the estimated sample covariance matrix, the Global Minimum Variance Portfolio (GMVP) is the solution of the minimization exercise given by the formula:

$\min _{W \in R} W^{\prime} \sum^{\wedge} W$

s.t. $\sum_{i=1}^{n} W i, t=1$

where Wi,t denotes the weight of asset $\mathrm{i}$ at period t. The constraint in equation 3 implies that the total portfolio weight, including short positions, should sum up to 1 . This is the classical unconstrained minimum variance portfolio, where the optimization exercise may result in just a few assets with extreme long and short positions included in the portfolio. 
The work of Jagannathan and Ma (2003) introduces the shrinkage like effect of the additional no short sale constrain and upper bound constraint, presented below in equation 4 and 5, of minimum variance portfolio since both of them have delivered accordingly promising out of sample performance results.

$W i, t \geq 0$, for $i=1 \ldots n$

$W i, t \leq W^{\max }$, for $i=1 \ldots n$

The risk reduction characteristics of three portfolios, namely unconstrained, no short sale constrained, no short sale and upper bound constrained for global assets, global equities, and global bond GMVP are analyzed in this paper.

\subsection{Transaction Costs}

Transaction costs in the time series of portfolio returns are calculated in accordance with the methodology suggested by Balduzzi and Lynch (1999) and further developed in the work of DeMiguel et al. (2009a) for the three minimum variance portfolios and the benchmarks. Let Rp denote the portfolio return before the revision, which is given by the formula:

$R p=\sum_{i=1}^{n} R i, t+1 * W i, t$

The rebalance of the portfolio at time $\mathrm{t}+1$ will upsurge a trade with a magnitude of $|\mathrm{Wi}, \mathrm{t}+1-\mathrm{Wi}, \mathrm{t}|$. Let $\mathrm{c}$ denote the proportional transaction $\operatorname{cost}^{2}$. After each revision period the overall transaction cost will be:

$c * \sum_{i=1}^{n}|\mathrm{Wi}, \mathrm{t}+1-\mathrm{Wi}, \mathrm{t}|$

The Wealth net of transaction cost at time $t+1$ can be written as:

Wealth $_{t+1}=$ Wealth $_{t} *(1+R p) *\left[1-c * \sum_{i=1}^{n}|\mathrm{Wi}, \mathrm{t}+1-\mathrm{Wi}, \mathrm{t}|\right]$

The Return net of transaction cost is given:

$R n=\frac{\text { Wealth }_{t+1}}{\text { Wealth }_{t}}-1$

The same approach is repeated at the end of each period for all portfolios and benchmarks. The revision frequency for the GMVP is assumed one year and three years. Since benchmarks, in general, are passive portfolio strategies that are characterized by low management costs and low trading volumes, we adopt a less frequent portfolio rebalancing for the value and equally weighted benchmark.

\section{DATA}

The data used in this research are monthly returns of regional bond, equity indices and global oil, gold indices chosen from DATASTREAM database software package available at ALBA Graduate Business School. The period under consideration is December 1996 - May 2013.

Table 1 lists the global asset portfolio indices. For equity and bonds the world is assumed divided in four regions, in order to identify different risk-return profiles from each other. Moreover, the bond market for Europe and

\footnotetext{
${ }^{2}$ In this research transaction costs will be assumed 50 basis point (bps) and $25 \mathrm{bps}$.
} 
US, is divided in corporate and government sections for encompassing a clearer picture of which segment affects the performance behavior of GMVP and/or benchmarks, since more indices with longer time series are available For Barclays Emerging Market World All Series bond index DATASTREAM reports capital gains, but not total returns (including coupon). We add a total yearly return of 5\% split monthly for approximating the coupon rate. The modification refers to the capital gain/coupon rate features of the Barclays EM Bond Indices. On May 23, 2014 reports a Yield To Maturity (YTM) of approx. 5.8\% and capital gain of approximately 1\%, at Benchmark Index Returns - daily updates from Barclays. We assume that the current yield of the index has been constant through all the period under consideration.

Table 1: Global Asset Portfolio Constituents

\begin{tabular}{|c|c|}
\hline CGBI WGBI EU ALL MATS & Europe Gov. Bond Index \\
\hline REX GENERAL BOND & Europe Corp. Bond Index \\
\hline CGBI USBIG OVERALL ASIA PACIFIC & Asia Pacific Bond Index \\
\hline BARCLAYS EM WORLD ALL SERIES* & Emerging World Bond Index \\
\hline ML CORP MASTER & US Corp. Bond Index \\
\hline CGBI WGBI US ALL MATS & US Gov. Bond Index \\
\hline MSCI EUROPE & European Stock Index \\
\hline MSCI EM :I & Emerging World Stock Index \\
\hline MSCI AC ASIA PACIFIC & Asia Pacific Stock Index \\
\hline MSCI USA & US Stock Index \\
\hline MLCX Gold & Gold Index \\
\hline S\&P GSCI Crude Oil & Oil Index \\
\hline \multicolumn{2}{|c|}{$\begin{array}{l}\text { The table reports the indices used for constructing through optimization the global minimum variance portfolio of the global } \\
\text { assets that comprises stocks, bonds, gold and oil. The time series of monthly returns are taken into consideration for each } \\
\text { index. The data are available for the period December } 1996 \text { - May 2013. The same data are used to construct benchmark } \\
\text { number } 2 \text {, the equally weighted portfolio }(1 / \mathrm{N}) \text {. The source is DATASTREAM database package available at ALBA } \\
\text { Graduate Business School. }\end{array}$} \\
\hline
\end{tabular}

The value weighted benchmark of the global asset minimum variance portfolio is the portfolio invested $60 \%$ on MSCI WORLD INDEX (equity global index) and 40\% in JPM GLOBAL BROAD INDEX (bond global index), a common benchmark, as emphasized by Hensel and Ziemba (1995) and Asness et al (2012), used to assess investment performance among different asset classes. The second benchmark is the equally weighted portfolio constructed with the twelve indices included in Table 1 . The benchmarks are rebalanced every 5 years.

Referring to the global bond portfolio, in addition to the previous indices, there are added two spreads reflecting risk premium of global long term government bonds in excess to short term government bonds and risk premium of global corporate bonds in excess to long term government bonds. This choice is made to observe how spread strategies reflecting differences in risk affect the optimization and performance of GMVP and benchmark.

The value weighted benchmark of the bond GMVPs is JPM GLOBAL BROAD INDEX and the second benchmark is the equally weighted portfolio invested in GMVP constituents. The second benchmark is rebalanced every 5 years.

The global oil index and global gold index are included in the equity portfolio due to the similarity of their risk-return attitude with the equity indices. Two spread strategies, representing the global risk premium of small capitalized stocks in excess to large capitalized and global risk premium of value stocks in excess to growth stocks, are considered in global equity portfolio.

The value weighted benchmark of the equity GMVP is the MSCI WORLD INDEX. The second benchmark is the equally weighted portfolio of GMVP constituents. The second benchmark is rebalanced every five years. All returns used in this research are EURO returns. 


\section{EMPIRICAL ANALYSIS}

Considering the performance statistics from the portfolio constituents ${ }^{3}$, stocks seem to be riskier than bonds in terms of standard deviation of returns on a global level.

What seems more interesting, however, is the extent for international diversification implied by Tables 2 where the correlation matrix among global assets, global bonds and global stock indices for the period under consideration is presented.

Table 2: Monthly Return Correlation Matrix of the Global Asset Portfolio

\begin{tabular}{|c|c|c|c|c|c|c|c|c|c|c|c|c|}
\hline & $\begin{array}{l}\text { Europe } \\
\text { G.B.I. }\end{array}$ & $\begin{array}{c}\text { Europe } \\
\text { C.B.I. }\end{array}$ & $\begin{array}{c}\text { Asia Pacific } \\
\text { B.I. }\end{array}$ & $\begin{array}{l}\text { Emerging } \\
\text { World B.I. }\end{array}$ & US C.B.I. & US G.B.I. & $\begin{array}{l}\text { European } \\
\text { S.I. }\end{array}$ & $\begin{array}{l}\text { Em. World } \\
\text { S.I. }\end{array}$ & $\begin{array}{c}\text { Asia Pacific } \\
\text { S.I. }\end{array}$ & US S.I. & Gold I. & Oil I. \\
\hline Europe G.B.I. & 1.00 & 0.83 & 0.27 & 0.09 & 0.33 & 0.36 & -0.15 & -0.15 & -0.07 & -0.12 & 0.07 & -0.12 \\
\hline Europe C.B.I. & 0.83 & 1.00 & 0.19 & -0.04 & 0.24 & 0.34 & -0.33 & -0.28 & -0.20 & -0.25 & 0.12 & -0.17 \\
\hline Asia Pacific B.I. & 0.27 & 0.19 & 1.00 & 0.66 & 0.94 & 0.91 & 0.08 & 0.18 & 0.30 & 0.39 & 0.31 & 0.12 \\
\hline $\begin{array}{l}\text { Emerging World } \\
\text { B.I. }\end{array}$ & 0.09 & -0.04 & 0.66 & 1.00 & 0.63 & 0.45 & 0.36 & 0.61 & 0.50 & 0.49 & 0.34 & 0.15 \\
\hline US C.B.I. & 0.33 & 0.24 & 0.94 & 0.63 & 1.00 & 0.90 & 0.19 & 0.19 & 0.32 & 0.44 & 0.27 & 0.10 \\
\hline US G.B.I. & 0.36 & 0.34 & 0.91 & 0.45 & 0.90 & 1.00 & -0.06 & -0.04 & 0.13 & 0.26 & 0.27 & 0.03 \\
\hline European S.I. & -0.15 & -0.33 & 0.08 & 0.36 & 0.19 & -0.06 & 1.00 & 0.60 & 0.71 & 0.79 & -0.08 & 0.13 \\
\hline $\begin{array}{l}\text { Emerging World } \\
\text { S.I. }\end{array}$ & -0.15 & -0.28 & 0.18 & 0.61 & 0.19 & -0.04 & 0.60 & 1.00 & 0.69 & 0.53 & 0.18 & 0.29 \\
\hline Asia Pacific S.I. & -0.07 & -0.20 & 0.30 & 0.50 & 0.32 & 0.13 & 0.71 & 0.69 & 1.00 & 0.68 & 0.15 & 0.18 \\
\hline US S.I. & -0.12 & -0.25 & 0.39 & 0.49 & 0.44 & 0.26 & 0.79 & 0.53 & 0.68 & 1.00 & 0.00 & 0.11 \\
\hline Gold I. & 0.07 & 0.12 & 0.31 & 0.34 & 0.27 & 0.27 & -0.08 & 0.18 & 0.15 & 0.00 & 1.00 & 0.15 \\
\hline Oil I. & -0.12 & -0.17 & 0.12 & 0.15 & 0.10 & 0.03 & 0.13 & 0.29 & 0.18 & 0.11 & 0.15 & 1.00 \\
\hline
\end{tabular}

The minimum (maximum) correlation coefficient of global asset presented in Table 2 is -0.33 (0.94), while the min-max correlation range for global bond (-0.65-0.94) and stock (-0.14-0.79) indices show the similar diversification appeal. Moreover, $75 \%(20 \%)$ of the correlation coefficient of global assets in table 2 are lower than $0.5(0)$. Global bond and stock portfolio constituents experience analogous covariation for the period under consideration.

These results signal the insight that the minimum variance optimization exercise applied in the global framework results in some interesting findings regarding risk reduction portfolio strategies highly mentioned in the literature.

This section continues with the analysis of risk reduction of GMVPs. Section 4 closes with the analysis of one special case, the implication in GMVP results from the change in revision frequency (from one year to three years).

\footnotetext{
${ }^{3}$ The summary statistics table is not included in this work. However, authors will make it available upon request.
} 


\subsection{GMVP Risk Reduction}

Referring to the results presented in Table 3, monthly unconstrained GMVPs experienced the best out of sample performance in terms of risk reduction. This observation is valid for the global asset, global bond, global equity GMVPs and respective benchmarks. When 50 bps transaction cost is imposed, however, the no short sale constrained minimum variance portfolio of global asset standard deviation $(2.55 \%)$ is lower than the standard deviation of unconstrained GMVP (2.66\%), no-short sale and upper bound constrained GMVP (4.97\%), value weighted $(7.87 \%)$ and equally weighted $(8.34 \%)$ benchmark.

These deductions are consistent in the change of revision frequency from one year to three years, as can be evidenced from table 4. Furthermore, for the global asset and global bond portfolio case, less frequent revision generally ${ }^{4}$ show in a slight decrease of out of sample risk. This is not the case of global stock GMVPs, where risks seem to decrease when portfolios are rebalanced more frequently. This mixed result is consistent with the suggestion of Behr et al (2008), who advise more research regarding the causality between revision frequency and standard deviation.

Table 3: Summary Statistics of Monthly GMVP and Benchmarks - 1 Year Revision Frequency

\begin{tabular}{|c|c|c|c|c|c|c|c|c|}
\hline \multirow[b]{2}{*}{ Global Assets } & \multicolumn{4}{|c|}{50 bps Transaction Cost } & & \multicolumn{3}{|c|}{25 bps Transaction Cost } \\
\hline & Mean & Std. Dev. & Max. & Min. & Mean & Std. Dev. & Max. & Min. \\
\hline Unconstrained GMVP & $5.15 \%$ & $2.66 \%$ & $35.14 \%$ & $-21.44 \%$ & $5.14 \%$ & $2.43 \%$ & $26.63 \%$ & $-21.44 \%$ \\
\hline Constrained GMVP & $5.25 \%$ & $2.55 \%$ & $29.10 \%$ & $-21.05 \%$ & $5.25 \%$ & $2.53 \%$ & $25.91 \%$ & $-21.05 \%$ \\
\hline Max. Constrained GMVP & $5.48 \%$ & $4.97 \%$ & $50.51 \%$ & $-39.72 \%$ & $5.48 \%$ & $4.96 \%$ & $50.51 \%$ & $-39.72 \%$ \\
\hline Benchmark 1 & $3.39 \%$ & $7.87 \%$ & $64.52 \%$ & $-82.55 \%$ & $3.39 \%$ & $7.87 \%$ & $64.52 \%$ & $-82.55 \%$ \\
\hline $\begin{array}{l}\text { Benchmark } 2 \\
\text { Global Bond }\end{array}$ & $5.59 \%$ & $8.34 \%$ & $73.75 \%$ & $-92.73 \%$ & $5.59 \%$ & $8.34 \%$ & $73.75 \%$ & $-92.73 \%$ \\
\hline Unconstrained GMVP & $1.69 \%$ & $2.14 \%$ & $29.70 \%$ & $-36.81 \%$ & $1.69 \%$ & $1.86 \%$ & $21.66 \%$ & $-28.92 \%$ \\
\hline Constrained GMVP & $2.91 \%$ & $2.34 \%$ & $19.96 \%$ & $-21.75 \%$ & $2.90 \%$ & $2.30 \%$ & $18.66 \%$ & $-18.79 \%$ \\
\hline Max. Constrained GMVP & $3.55 \%$ & $2.73 \%$ & $25.26 \%$ & $-18.00 \%$ & $3.55 \%$ & $2.71 \%$ & $25.26 \%$ & $-18.00 \%$ \\
\hline Benchmark 1 & $3.37 \%$ & $7.20 \%$ & $106.85 \%$ & $-44.99 \%$ & $3.37 \%$ & $7.20 \%$ & $106.85 \%$ & $-44.99 \%$ \\
\hline $\begin{array}{l}\text { Benchmark } 2 \\
\text { Global Equity }\end{array}$ & $4.32 \%$ & $5.03 \%$ & $52.58 \%$ & $-41.18 \%$ & $4.32 \%$ & $5.02 \%$ & $52.58 \%$ & $-41.18 \%$ \\
\hline Unconstrained GMVP & $3.35 \%$ & $4.71 \%$ & $50.88 \%$ & $-58.01 \%$ & $3.35 \%$ & $4.69 \%$ & $50.88 \%$ & $-58.01 \%$ \\
\hline Constrained GMVP & $3.82 \%$ & $4.91 \%$ & $47.93 \%$ & $-51.29 \%$ & $3.82 \%$ & $4.91 \%$ & $47.93 \%$ & $-51.29 \%$ \\
\hline Max. Constrained GMVP & $5.81 \%$ & $7.22 \%$ & $57.06 \%$ & $-88.67 \%$ & $5.81 \%$ & $7.22 \%$ & $57.06 \%$ & $-88.67 \%$ \\
\hline Benchmark 1 & $3.59 \%$ & $14.19 \%$ & $138.44 \%$ & $-139.87 \%$ & $3.59 \%$ & $14.19 \%$ & $138.44 \%$ & $-139.87 \%$ \\
\hline Benchmark 2 & $7.23 \%$ & $11.51 \%$ & $86.60 \%$ & $-140.08 \%$ & $7.23 \%$ & $11.51 \%$ & $86.60 \%$ & $-140.08 \%$ \\
\hline $\begin{array}{l}\text { The table reports the montl } \\
\text { minimum return for the peri } \\
\text { class portfolio, global bond } \\
\text { described in the methodolo } \\
\text { realized returns are net of tra }\end{array}$ & imi & 等 & ssumed & nd mon & 14 app & esults. & annualize & $\begin{array}{l}\text { aximum and } \\
\text { global as set } \\
\text { estimated as }\end{array}$ \\
\hline
\end{tabular}

Upper bound constrained GMVP strategies, however, in all scenarios, experience a higher return than other portfolio strategies, except the equally weighted portfolio. Results remain the same with the change of revision frequency. For the global asset and global equity case, however, GMVPs restricted by no-short sale and maximum weight, experience, regardless the transaction cost imposed, higher expected return when portfolios are rebalanced more frequently.

The main conclusion from this section is that, no matter the assumed revision frequency or transaction cost, unconstrained GMVPs seem to experience a lower out of sample risk as compared with constrained GMVPs and benchmarks for the global asset, bond and stock case. Whether risk reduction is statistically significant, however, it

\footnotetext{
${ }^{4}$ There is one exception, the Global Bond Max. Constrained GMVP, where the realized risk is lower in one year revision frequency than in two years revision frequency.
} 
is not examined in this paper. Max constrained GMVP strategy appears the best strategy for investors who prefer higher expected return independently from the risk.

Table 4: Summary Statistics of Monthly GMVP and Benchmarks - 3 Year Revision Frequency

\begin{tabular}{|c|c|c|c|c|c|c|c|c|}
\hline & \multicolumn{4}{|c|}{50 bps transaction cost } & \multicolumn{4}{|c|}{25 bps transaction cost } \\
\hline Global Assets & Mean & Std. Dev. & Max. & Min. & Mean & Std. Dev. & Max. & Min. \\
\hline $\begin{array}{l}\text { Unconstrained } \\
\text { GMVP }\end{array}$ & $5.01 \%$ & $2.59 \%$ & $31.61 \%$ & $-28.39 \%$ & $5.00 \%$ & $2.36 \%$ & $26.63 \%$ & $-23.49 \%$ \\
\hline Constrained GMVP & $5.07 \%$ & $2.51 \%$ & $29.10 \%$ & $-22.17 \%$ & $5.07 \%$ & $2.49 \%$ & $25.91 \%$ & $-22.17 \%$ \\
\hline $\begin{array}{l}\text { Max. Constrained } \\
\text { GMVP }\end{array}$ & $5.82 \%$ & $4.92 \%$ & $50.51 \%$ & $-40.14 \%$ & $5.82 \%$ & $4.91 \%$ & $50.51 \%$ & $-40.14 \%$ \\
\hline Benchmark 1 & $3.39 \%$ & $7.87 \%$ & $64.52 \%$ & $-82.55 \%$ & $3.39 \%$ & $7.87 \%$ & $64.52 \%$ & $-82.55 \%$ \\
\hline $\begin{array}{l}\text { Benchmark } 2 \\
\text { Global Bond }\end{array}$ & $5.59 \%$ & $8.34 \%$ & $73.75 \%$ & $-92.73 \%$ & $5.59 \%$ & $8.34 \%$ & $73.75 \%$ & $-92.73 \%$ \\
\hline $\begin{array}{l}\text { Unconstrained } \\
\text { GMVP }\end{array}$ & $1.42 \%$ & $2.11 \%$ & $27.01 \%$ & $-36.81 \%$ & $1.42 \%$ & $1.83 \%$ & $18.75 \%$ & $-28.92 \%$ \\
\hline Constrained GMVP & $2.66 \%$ & $2.28 \%$ & $18.22 \%$ & $-21.75 \%$ & $2.66 \%$ & $2.23 \%$ & $18.22 \%$ & $-18.79 \%$ \\
\hline $\begin{array}{l}\text { Max. Constrained } \\
\text { GMVP }\end{array}$ & $3.46 \%$ & $2.75 \%$ & $25.26 \%$ & $-18.00 \%$ & $3.46 \%$ & $2.73 \%$ & $25.26 \%$ & $-18.00 \%$ \\
\hline Benchmark 1 & $3.37 \%$ & $7.20 \%$ & $106.85 \%$ & $-44.99 \%$ & $3.37 \%$ & $7.20 \%$ & $106.85 \%$ & $-44.99 \%$ \\
\hline $\begin{array}{l}\text { Benchmark } 2 \\
\text { Global Equity }\end{array}$ & $4.32 \%$ & $5.03 \%$ & $52.58 \%$ & $-41.18 \%$ & $4.32 \%$ & $5.02 \%$ & $52.58 \%$ & $-41.18 \%$ \\
\hline $\begin{array}{l}\text { Unconstrained } \\
\text { GMVP }\end{array}$ & $3.38 \%$ & $5.06 \%$ & $49.79 \%$ & $-78.33 \%$ & $3.38 \%$ & $5.06 \%$ & $49.79 \%$ & $-78.33 \%$ \\
\hline Constrained GMVP & $3.98 \%$ & $5.08 \%$ & $49.53 \%$ & $-77.67 \%$ & $3.98 \%$ & $5.08 \%$ & $49.53 \%$ & $-77.67 \%$ \\
\hline $\begin{array}{l}\text { Max. Constrained } \\
\text { GMVP }\end{array}$ & $6.36 \%$ & $7.49 \%$ & $70.84 \%$ & $-115.58 \%$ & $6.36 \%$ & $7.49 \%$ & $70.84 \%$ & $-115.58 \%$ \\
\hline Benchmark 1 & $3.59 \%$ & $14.19 \%$ & $138.44 \%$ & $-139.87 \%$ & $3.59 \%$ & $14.19 \%$ & $138.44 \%$ & $-139.87 \%$ \\
\hline Benchmark 2 & $7.23 \%$ & $11.51 \%$ & $86.60 \%$ & $-140.08 \%$ & $7.23 \%$ & $11.51 \%$ & $86.60 \%$ & $-140.08 \%$ \\
\hline
\end{tabular}

The table reports the monthly optimization annualized first and second moments of returns results. The annualized maximum and minimum return for the period under observation for the unconstrained, constrained and maximum constrained GMVPs of global asset class portfolio, global bond portfolio, global equity portfolio and related benchmarks after the sample covariance matrix is estimated as described in the methodology section and optimization is run. The portfolio rebalancing/reinvestment period is one year. Monthly realized returns are net of transaction costs, which were assumed 50 bps or 25 bps and applied as described in equation (8).

\section{CONCLUDING REMARKS}

This paper studies the risk reduction features of of global minimum variance portfolios for global assets, global stocks and global bonds. In this study, the world is divided in four regions: US, Europe, Asia - Pacific and Developing Countries. International indices of stocks, corporate/government bonds, spreads, oil and gold monthly returns served as input in the optimization exercise. GMVPs are derived using the unrestricted and upper/lower bound restricted portfolio weights in the sample covariance matrix methodology introduced by Jagannathan and Ma (2003).

Unconstrained GMVPs seem to provide the greatest reduction of risk, while most restrictive minimum variance portfolios result in the highest return, which is valid for global assets, and segmented markets of stocks and bonds. This result does not change independently from the transaction costs or revision frequency.

To the best of our knowledge, this is the first study that takes into consideration global asset classes to estimate and compare the out of sample risk reduction of global minimum variance portfolios.

A broader consideration of asset classes, such as real estate and/or labor income, suggested by Healton and Lucas (2000), may produce better performing minimum variance portfolios, since more assets, financial and nonfinancial, would be considered in that study. A more robust portfolio optimization exercise may be one that 
allows transaction costs vary among difference countries and regions, which would be related with the financial trading volume of each constituent. The same exercise may be considered by including, instead of indices, the top 5 to 10 stocks and bonds (corporate and government) of different regions and/or countries. This strategy would maybe highlight even more the risk reduction power of international diversification.

\section{AUTHOR INFORMATION}

\section{Agim Kukeli (agim.kukeli@bhsu.edu)}

Ph.D. (2004) in Economics, Colorado State University, Colorado, USA. Dr. Kukeli currently teaches economics at Black Hills State University, School of Business. He has been teaching at the Colorado Mesa University, Colorado State University, University of New York in Tirana, University of New York Prague, etc. economics and finance courses at both undergraduate and graduate level. His research interests are Monetary Theory and Policy, Foreign Direct Investment, Market Structure (Game theory), Financial Markets and Price Variability.

\section{Arben Zibri (arbenzibri@unyt.edu.al)}

Doctoral Candidate (2015, expected) in Economics, University "Aleksander Mojsiu”, Durres, Albania. Arben Zibri is Senior Relationship Manager at Alpha Bank Albania and lecturer of finance at University of New York in Tirana and Epoka University, Albania. He has taught at undergraduate and graduate courses such as Portfolio Management, Corporate Finance, and Financial Institution and Markets. His research interests are Portfolio Theory, Capital Markets, Empirical Finance, Performance Analysis, and Market Risk.

\section{ACKNOWLEDGEMENTS}

The research has been supported by ALBA Graduate Business School, Athens, through the access to DATASTREAM. We thank Nikolaos Tessaromatis from EDHEC Business School, and Athanasios Sakkas and Christos Cabolis from ALBA Graduate Business School for their great help and support with the data and academic feedback. We thank the participants at the 2014 International Business Conference in Munich organized by the Clute Institute for their helpful comments.

\section{REFERENCES}

1. Asness, C., Frazzini, A. \& Pedersen, L. (2012), Leverage Aversion and Risk Parity. Financial Analyst Journal, 68 (1), 47-59.

2. Balduzzi, P. \& Lynch, A. (1999). Transaction costs and predictability some utility cost calculations. Journal of Financial Economics, 52 (1), 47-78.

3. Behr, P., Guettler, A., \& Miebs, F. (2013, April). On portfolio optimization: Imposing the right constraints. Journal of Banking and Finance, 37(4), 1232-1242.

4. Behr, P., Guettler, A., \& Miebs, F. (2008, September). Is minimum-variance investing really worth the while? An analysis with robust performance inference. (Working Paper).

5. Berens, T., Wied, D., \& Ziggel, D. (2013, May). A completely automated optimization strategy for global minimum-variance portfolios based on a new test for structural breaks. Sonderforschungsbereich (SFB) 823, Discussion Paper No. 19.

6. Bodnar, T. \& Okhrin, Y. (2013). Boundaries of the risk aversion coefficient: Should we invest in the global minimum variance portfolio?. Applied Mathematics and Computation, 219 (10), 5440-5448.

7. Bodnar, T., Parolya, N. \& Schmid, W. (2014, June). Estimation of the Global Minimum Variance Portfolio in High Dimensions. Working Paper.

8. Chan, L. K. C., Karceski, J., \& Lakonishok, J. (1999, Winter). On portfolio optimization: Forecasting covariances and choosing the risk model. The Review of Financial Studies, 12(5), 937-974.

9. Chopra, K. V., \& Ziemba, T. W. (1993, Winter). The effect of errors in means, variances, and covariances on optimal portfolio choice. Journal of Portfolio Management, 19(2), 6-11.

10. Clarke, R., de Silva, H., Thorley, S. (2006, Fall). Minimum-variance portfolios in the U.S. equity market. The Journal of Portfolio Management, 33(1), 10-24. 
11. Clarke, R., de Silva; H., \& Thorley, S. (2011, Winter). Minimum-variance portfolio composition. The Journal of Portfolio Management, 37(2), 31-45.

12. DeMiguel, V. Garlappi, L., \& Uppal, R. (2009, May). Optimal versus naïve diversification: How inefficient is the 1/n portfolio strategy? The Review of Financial Studies, 22(5), 1915-1953.

13. DeMiguel, V., Garlappi, L., Nogales J. F., \& Uppal, R. (2009, May). A generalized approach to portfolio optimization: Improving performance by constraining portfolio norms. Management Science, 55(5), 798812.

14. Fama, E., \& French, K. (1993, Feb.). Common risk factors in the returns on stocks and bonds. Journal of Financial Economics, 33(1), 3-56.

15. Frahm, G., \& Memmel, C. (2010, Dec.). Dominating estimators for the global minimum variance portfolios. Journal of Econometrics, 159(2), 289-302.

16. Frahm, G. (2010, Dec.). Linear statistical inference for global and local minimum variance portfolios. Springer Statistical Papers, 51(4), 789-812.

17. Healton, J., \& Lucas, D. (2000, June). Portfolio choice and asset prices: The importance of entrepreneurial risk. The Journal of Finance, 55(3), 1163-1198.

18. Hensel, Ch. \& Ziemba, W. (1995). .United States Investment Returns during Democratic and Republican Administrations, 1928-1993. Financial Analyst Journal, 51 (2), 61-69.

19. Hollifield, B., \& Green, R. (1992, Dec.). When will mean-variance efficient portfolios be well diversified? The Journal of Finance, XLVII(5), 1785-1809

20. Kempf, A., \& Memmel, C. (2006, Oct.). Estimating the global minimum variance portfolio. Schmalenbach Business Review (SBR), 58, 332-348.

21. Kosowski, R. Narayan, N. Y., \& Teo, M. (2007, April). Do hedge funds deliver alpha? A bayesian and bootstrap analysis. Journal of Financial Economics, 84(1), 229-264.

22. Jagannathan, R., \& Ma, T. (2003, Aug.). Risk reduction in large portfolios: Why imposing the wrong constraints helps. The Journal of Finance, LVIII(4).

23. Ledoit, O., \& Wolf, M. (2003, Dec.). Improved estimation of the covariance matrix of stock returns with an application to portfolio selection. Journal of Empirical Finance, 10(5), 603-621.

24. Ledoit, O., \& Wolf, M. (2004, Summer). Honey, I shrunk the sample covariance matrix. The Journal of Portfolio Management, 30(4), 110-119.

25. Ledoit, O., \& Wolf, M. (2008, Dec.). Robust performance hypothesis testing with the Sharpe ratio. Journal of Empirical Finance, 15(5), 850-859.

26. Ledoit, O. and Wolf, M. (2014, Jan.). Nonlinear Shrinkage of the Covariance Matrix for Portfolio Selection: Markowitz meets Goldilocks. Working Paper.

27. Markowitz, H. (1952, March). Portfolio selection. The Journal of Finance, 7(1), 77-91.

28. Nielsen, F., \& Aylursubramanian, R. (2008, April). Far from the Madding Crowd-Volatility Efficient Indices. MSCI Barra Research.

29. Pantaleo, E. Tumminello, M., Lillo, F., \& Mantegna, N. R. (2011, July). When do improved covariance matrix estimators enhance portfolio optimization? An empirical comparative study of nine estimators. Quantitative Finance, 11(7), 1067-1080.

30. Poullaouec, T. (2008, Oct.). Things to consider when investing in minimum variance strategies. State Street Global Advisor.

31. Roll, R. (1992, Summer). A mean/variance analysis of tracking error. The Journal of Portfolio Management, 18(4), 13-22.

32. Sharpe, W. (1964, Sept.). Capital asset prices: A theory of market equilibrium under conditions of risk. The Journal of Finance, 19(3), 425-442. 